\title{
Research on the Efficiency of Science and Technology Input and Output in Provinces along the Belt and Road Based on DEA Model
}

\author{
Wenwen Chen \\ School of Economics \& Management, Nanjing University of Science \& Technology, Nanjing \\ 210094, China. \\ alisachen2015@163.com
}

Keywords: DEA model; One Belt and One Road; Input-output efficiency of science and technology; Malmquist index.

\begin{abstract}
Since 2013, president Xi Jinping proposed the strategic concept of "One Belt and One Road". The implementation of this strategy needs to be implemented with a scientific concept of development so as to deepen the lead role of science and technology input in the economic and social development in all regions. On the basis of the existing literature, this paper establishes the evaluation index system of science and technology input-output efficiency of provinces and cities along the "One Belt and One Road". By combining the DEA and Malmquist index method, this paper makes a comprehensive and partial analysis on the efficiency of science and technology input-output of provinces and cities along the line from 2011 to 2015 Comparative analysis to provide advice for the development of the science and technology industry and economic development of the provinces along the Belt and Road.
\end{abstract}

\section{Introduction}

The implementation of the "One Belt and One Road" strategy is conducive to promoting the complementarity of resources in the eastern, central and western regions and deepening regional exchanges and cooperation. As the background of the times changes, science and technology are increasingly becoming decisive factors in the competition of comprehensive national strength. Scientific and technological innovations often reflect the regional innovation system. The level of operation, while the efficiency of science and technology investment is an important indicator of the allocation of regional scientific and technological resources and operational capabilities.

Data envelopment analysis (DEA) was first proposed by A. Charens, WWCooper and E. Rhodes et al. in 1978 and gradually introduced into CRS model. Later, scholars put forward VRS model, FC model, super efficiency DEA model and three-stage DEA model for the comprehensive evaluation of the same type of multi-input and multi-output index efficiency research method [1]. According to the existing literature, foreign scholars generally use the DEA empirical research in the production field of an industry, and achieved great results, but rarely applied to scientific and technological activities. Domestically, Lv Chen et al. used the DEA method to evaluate the efficiency of science and technology input-output activities in provincial areas in China [2]. Wang Keying et al. used random frontier production function to measure the production efficiency along the Belt and Road regions and analyzed the main influencing factors [3].

In summary, this paper will analyze the differences in science and technology input-output efficiency between provinces and cities along the "One Belt and One Road" between 2011 and 2015 and discuss the changes in the input-output efficiency of science and technology and the causes of efficiency changes in 18 provinces before and after the implementation of the strategy to provide references of increasing scientific and technological input-output efficiency.

\section{Research Methods}

Data Envelopment Analysis is DEA method. DEA is used to evaluate the relative validity of decision-making units under multi-input and multi-output conditions. It does not need to consider the 
form of production function and is a non-parameter analytical method, its outstanding merit is that it does not need to consider the production function form. The DEA method is mainly composed of two models: the CRS model and the VRS model, assuming the CRS model with constant returns to scale, and obtaining the comprehensive efficiency(pe) and the VRS with variable returns to scale model to obtain pure technical efficiency (pte) and scale return efficiency (se). The relationship between the three is: $p e=$ pte $\times$ se.

The Malmquist Index was proposed by Malmquist Sten in 1953, is widely used to measure changes in productivity. The Malmquist Index analyzes the change in efficiency over a period of time due to the inability of the production frontier to stay on the same frontier. In the CRS model, total factor productivity change (tfpch) can be decomposed into technical improvements (techch) and integrated technical efficiency changes (effch). In the VRS model, the integrated technical efficiency is further decomposed into pure technical efficiency changes (pech) and scale Efficiency change (sech), which is $\mathrm{tfpch}=$ techch $\times$ effch $=$ techch $\times$ pech $\times$ sech.

The Malmquist Index Method has been widely used in the measurement and evaluation of production efficiency in various industries. When $t f p c h>1$, it shows that the total factor productivity is the growth trend, on the contrary, it is a downward trend. Based on technology $\mathrm{T}$ in period $t$, the Malmquist Index based on output angle is calculated, and the formula is as follows:

$$
\begin{aligned}
& M_{0}{ }^{t}(T F P)=\left(x^{t+1}, y^{t+1}, x^{t}, y^{t}\right) \\
& M_{0}{ }^{t}(T F P)=\left(x^{t+1}, y^{t+1}, x^{t}, y^{t}\right) \\
& =d_{0}{ }^{t}\left(x^{t+1}, y^{t+1}\right) / d_{0}{ }^{t}\left(x^{t}, y^{t}\right)
\end{aligned}
$$

Based on technology $T$ in period $t$, Malmquist Index based on output angle:

$$
\begin{aligned}
& M_{0}{ }^{t+1}(\text { TFP })=\left(x^{t+1}, y^{t+1}, x^{t}, y^{t}\right) \\
& =d_{0}{ }^{t+1}\left(x^{t+1}, y^{t+1}\right) / d_{0}{ }^{t+1}\left(x^{t}, y^{t}\right)
\end{aligned}
$$

Take the geometric mean of the two as the Malmquist Index to measure the productivity change from period $t$ to $t+1$ :

$$
\begin{gathered}
M_{0}^{t, t+1}(T F P)=\left(x^{t+1}, y^{t+1}, x^{t}, y^{t}\right) \\
=d_{0}^{t}\left(x^{t}, y^{t}\right) / d_{0}^{t+1}\left(x^{t}, y^{t}\right) \\
T F P=\left[d_{0}^{t+1}\left(y^{t+1}, x^{t+1}\right) / d_{0}^{t}\left(y^{t+1}, x^{t+1}\right)\right] \times\left[d_{0}^{t+1}\left(y^{t}, x^{t}\right) / d_{0}{ }^{t}\left(y^{t}, x^{t}\right)\right] \\
=T E C \times T C P
\end{gathered}
$$

In the above equations, $\left(x^{t+1}, y^{t+1}\right)$ and $\left(x^{t}, y^{t}\right)$ represent the input and output vectors of the $t+1$ and $t$ period; $d_{0}{ }^{t}$ and $d_{0}{ }^{t+1}$ respectively represent the technology of period $t$ as a reference, the distance function for periods $t$ and $t+1$ periods; effect for the index of technological efficiency changes, and techch for the index of technological progress.

\section{Variable Selection and Data Source}

The data used in this paper come from the National Bureau of Statistics database to ensure the objectivity and accuracy of the calculations.

Based on the availability of existing research and data, this study considers the number of valid invention patents and technology market turnover as output indicators reflecting science and technology activities, internal expenditure of $R \& D$ funds, and $R \& D$ practitioners as input indicators 
reflecting science and technology activities. In this paper, the data of industrial enterprises above designated size in 18 provinces and municipalities along the Belt and Road along the route from 2011 to 2015 were selected to measure and analyze. Due to the lack of data in Tibet Autonomous Region, Tibet Autonomous Region was excluded for completeness, and finally the Belt and Road 17 provinces along the sample for analysis.

\section{Empirical Analysis}

\subsection{Calculation of Science and Technology Innovation Efficiency}

According to the model calculation, the comprehensive level of scientific and technological innovation efficiency in all provinces (see Table 1).

Table 1 . The efficiency of technological innovation

\begin{tabular}{ccccccc}
\hline DMU & 2011 & 2012 & 2013 & 2014 & 2015 & Mean \\
\hline Heilongjiang & 0.708 & 0.923 & 0.836 & 0.784 & 0.842 & 0.8186 \\
Jilin & 0.502 & 0.389 & 0.39 & 0.432 & 0.413 & 0.4252 \\
Liaoning & 0.66 & 0.674 & 0.576 & 0.506 & 0.465 & 0.5762 \\
Xinjiang & 0.619 & 0.698 & 0.981 & 1 & 1 & 0.8596 \\
Shanxi & 1 & 1 & 1 & 1 & 0.886 & 0.9772 \\
Gansu & 0.916 & 0.807 & 0.774 & 0.732 & 0.64 & 0.7738 \\
Neimenggu & 0.224 & 0.521 & 0.234 & 0.219 & 0.19 & 0.2776 \\
Qinghai & 1 & 1 & 1 & 1 & 1 & 1 \\
Ningxia & 0.28 & 0.268 & 0.334 & 0.374 & 0.369 & 0.325 \\
Chongqing & 0.898 & 0.84 & 0.961 & 0.87 & 0.801 & 0.874 \\
Guangxi & 0.343 & 0.343 & 0.503 & 0.611 & 0.708 & 0.5016 \\
Yunnan & 0.644 & 0.764 & 0.868 & 0.961 & 0.765 & 0.8004 \\
Shanghai & 1 & 1 & 0.886 & 0.894 & 0.574 & 0.8708 \\
Fujian & 0.457 & 0.434 & 0.498 & 0.523 & 0.691 & 0.5206 \\
Zhejiang & 1 & 1 & 1 & 1 & 1 & 1 \\
Guangdong & 0.599 & 0.506 & 0.559 & 0.645 & 0.634 & 0.5886 \\
Hainan & 0.772 & 0.481 & 0.643 & 0.678 & 0.712 & 0.6572 \\
Mean & 0.684 & 0.685 & 0.709 & 0.719 & 0.688 & 0.697 \\
Coastal & 0.764 & 0.668 & 0.728 & 0.761 & 0.759 & 0.736 \\
Northeast & 0.623 & 0.662 & 0.601 & 0.574 & 0.573 & 0.607 \\
Northwest & 0.808 & 0.859 & 0.865 & 0.865 & 0.817 & 0.843 \\
Southwest & 0.628 & 0.649 & 0.777 & 0.814 & 0.758 & 0.725 \\
\hline
\end{tabular}

Overall, the efficiency of science and technology innovation in 17 provinces along the Belt and Road of China fluctuated around 0.7 in 2011-2015. The efficiency of science and technology innovation in provinces along the provinces showed an overall upward trend, reaching as high as 0.719 in 2014. The efficiency of science and technology innovation in the coastal, northwest, and southwest regions has generally risen and fluctuate, while the Northeast region has risen first and then declined. This is because the state has increased investment in science and technology, attached great importance to education, and encouraged science and technology innovation. The "One Belt and One Road" policy has enabled the western region to introduce a large number of capital and technical personnel, and the level of innovation has grown by leaps and bounds. During the "13th Five-Year Plan"period, the country was in the stage of economic transformation. The old industrial bases in the northeast could hardly change the original economic model, showing slight technological innovation deficiencies. It showed a transition from labor-intensive to technology- and resource-intensive. However, the old industrial bases in the northeast could hardly change the original economic model, showing slight technological innovation.

\subsection{Analysis of Trend of Science and Technology Innovation Efficiency}

Substitute the data into DEAP 2.1 and calculate Table 2. 
Table 2. The Change of Science and Technology Innovation Efficiency

\begin{tabular}{cccccc}
\hline DMU & effch & techch & pech & sech & tfpch \\
\hline Heilongjiang & 1.044 & 1.07 & 1.049 & 0.995 & 1.117 \\
Jilin & 0.953 & 1.097 & 0.96 & 0.992 & 1.045 \\
Liaoning & 0.916 & 1.177 & 0.995 & 0.921 & 1.079 \\
Xinjiang & 1.127 & 1.164 & 1.112 & 1.014 & 1.312 \\
Shanxi & 0.97 & 1.254 & 1 & 0.97 & 1.216 \\
Gansu & 0.914 & 1.231 & 0.931 & 0.982 & 1.126 \\
Neimenggu & 0.959 & 1.153 & 0.988 & 0.971 & 1.106 \\
Qinghai & 1 & 1.396 & 1 & 1 & 1.396 \\
Ningxia & 1.071 & 1.072 & 1.046 & 1.025 & 1.148 \\
Chongqing & 0.972 & 1.12 & 1.024 & 0.948 & 1.088 \\
Guangxi & 1.198 & 1.111 & 1.217 & 0.985 & 1.332 \\
Yunnan & 1.044 & 1.131 & 1.041 & 1.003 & 1.181 \\
Shanghai & 0.87 & 1.168 & 0.989 & 0.88 & 1.016 \\
Fujian & 1.109 & 1.053 & 1.146 & 0.968 & 1.168 \\
Zhejiang & 1 & 1.019 & 1 & 1 & 1.019 \\
Guangdong & 1.014 & 1.08 & 1 & 1.014 & 1.096 \\
Hainan & 0.98 & 1.066 & 0.952 & 1.029 & 1.045 \\
Mean & 1.005 & 1.136 & 1.024 & 0.981 & 1.142 \\
\hline
\end{tabular}

From the above table, we can see that from 2011 to 2015 , China's TFP in the 17 provinces along the Belt and Road has increased at a rate of about $14.2 \%$, and $13.6 \%$ of technological progress is the main reason for the improvement of the efficiency of science and technology innovation. The efficiency of science and technology innovation along the province has always maintained a positive growth rate of TFP. However, there is still a problem of low technical efficiency. This is due to the lack of innovative conditions, and the related infrastructure and institutional systems are not yet perfect, and they cannot match the advanced technologies introduced.

\section{Conclusions and Recommendations}

In summary, the efficiency of science and technology input and output in the provinces along the Belt and Road Initiative has been increased. To achieve regional technological innovation and promote regional economic development, this paper puts forward the following recommendations: Local governments should increase scientific and technological input and attach importance to inputoutput efficiency. Use scientific and technological resources to achieve optimal scale; all localities should increase investment in education and science and technology, encourage scientific and technological exchanges, optimize the scale of science and technology input and output, and reverse the current state of low industrialization of scientific and technological achievements.

\section{References}

[1]. A. Charnel, W. W. Cooper \& E. Rhodes (1978). Measuring the Efficiency of Decision Making Units, European. Journal of Operational Research,2 (4),429-444.

[2]. Chen Lv, Mingbin Zeng. Research on the Relative Efficiency of Regional Science and Technology Input-output in China Based on DEA [J]. Science Management Research, 2014 (2): 101-104.

[3]. Keying Wang, Hongwu Zhang, Wanjun Shen. An Empirical Study on Production Technology Efficiency in China's Belt and Road Region - Based on the Analysis of Stochastic Frontier Production Function [J]. Business Economics, 2016.06: 141-145. 